\title{
The Relationship between Learning Vocabulary via Mobile (Mobile-Assisted Language Learning) and Iranian EFL Learners' Social Anxiety and Loneliness
}

\author{
Elham Mohammadi*, Azam Masoumi \\ Department of English Language and literatures, University of Zanjan, Iran
}

Received on: 17-8-2020

Accepted on: 28-12-2020

\begin{abstract}
The present study has investigated the relationship between learning English vocabulary via mobile phone and the learners' social anxiety and loneliness. The participants of the study were thirty-two intermediate English as foreign language (EFL) learners studying English at the University of Zanjan, Zanjan, Iran. Sixty American English idioms were chosen and became available in a Telegram channel, during a six-week period of treatment to provide the participants with Mobile-Assisted Language Learning (MALL). A researcher-designed achievement test was administered to assess the learners' vocabulary learning via mobile phone. Interaction Anxiousness Scale (IAS) (Leary 1983) and UCLA Loneliness Scale version 3 (ULS) (Russell 1996) were used to estimate the learners' social anxiety and loneliness, respectively. The results showed no significant correlation between the variables; thus, it can be concluded that MALL not only frees the learners from the restrictions of time and place, but also minimizes the possible intervention of some socially and emotionally affective variables, such as social anxiety and loneliness in the process of language learning.
\end{abstract}

Keywords: Learning Vocabulary, Mobile-assisted Language Learning, Social Anxiety, Loneliness

\section{Introduction}

New technologies have predominated many aspects of contemporary life. The prevalence of these technologies has convinced stakeholders to apply them in order to improve the efficacy of the learning process. One of these technologies is mobile phone, which provides a great opportunity for learners to access different kinds of sources, from e-books to visual and audial programs and softwares, aiming at improving the learners' success rate. People can use their mobile phone at any time and in any places. This feature frees learners from attending a class at a specific time and allows more flexibility on their daily schedules. Besides, mobile phone is a perfect tool for edutainment, which amuses learners and educates them simultaneously. Whatever the learners' purpose of learning a new language is, studying two fundamental realms is inevitable: grammar and vocabulary. Without having enough knowledge of vocabulary, it is impossible to comprehend and produce any utterances. Richards and Rodgers (2001) described the development of the Lexis Approach in the realm on second/foreign language learning and teaching based on the belief that the building block of language learning is lexis. Further, they explained

\footnotetext{
() 2021 JJMLL Publishers/Yarmouk University. All Rights Reserved,

* Doi: https://doi.org/ 10.47012/jjmll.13.4.10

*Corresponding Author: e_mohammadi@znu.ac.ir
} 
how the work of Corder (1973), Willis (1990), and Lewis (1993) remarkably enhanced the status of vocabulary in language teaching.

On the other hand, the emergence of learner-centered approach in the domain of language learning and teaching reveals the importance of learners' characteristics and strategies they utilize in order to be successful learners. Since learning a language via mobile is a personalized process, it seems necessary to investigate the role of learner-related variables such as anxiety and feelings of loneliness in the process of MALL. Traditional classrooms provide learners with face-to-face interaction with human teacher who may be trained how to behave when he/she encounters with students with different social and emotional characteristics, while MALL rules out such features. If there are any kinds of relationship between these learner-related features and their achievements in the process of MALL, it is possible to put more emphasis on the centrality of learners' characteristics and emotional status and, consequently, to encourage the mobile software developers to regard such features while designing their products. Furthermore, the role of loneliness on the part of language learners has been overlooked, while more emphasis has been put on the learners' personality traits and classroom anxiety, and specifically speaking anxiety. Nowadays, the hectic pace of technology development enunciates the prevalence of modern technologies which are capable of immediate interaction in the near future. Thus, recognition of the effective factors in the first place, and determining the role of these influential factors in the process of MALL, afterwards, can be highly beneficial in the domain of language learning.

The benefits of inclusion of new technologies, such as laptop, tablet, and smart phone are obvious in learning in general and language learning in particular. On the one hand, using related mobile programs has been considered as a viable method of language learning and specifically learning vocabulary (Al Saidi and Al Shezawi 2020, Bensalem 2018; Gürlüyer 2019; Kacetl and Klímová 2019; Korlu and Mede 2018; Li and Cummins 2019). On the other hand, the user of such mobile programs is a human being, who is identified as a complicated, multidimensional, and dynamic creature. All living things experience distinct situations and moods throughout their life; human as one of the smartest beings on the Earth is prone to the wide range of variation in his/her physical and mental situations affecting his/her capability of doing everything from understanding and learning to acting and responding. Therefore, learner's mental and emotional conditions may play an important role in the process of language learning as well as his/her physical status.

Speaking a language is a unique feature of human being and is regarded as the basic tool for effective communication, as parents try, wait and hope to hear their children speak. To expand the knowledge and become familiar with other cultures, learning foreign languages seems to be vital. Reviewing the history of language learning and teaching, we encounter different approaches and methods being attempted to become more fruitful. During the evolutionary development of language learning methods, the usage of new inventions that facilitate the process of language learning is substantial. Nowadays, with rapid enhancement in mobile technologies, especially smartphones, and considering accessibility, inexpensiveness, and applicability of these devices, it is reasonable to apply them in the 
The Relationship between Learning Vocabulary via Mobile (Mobile-Assisted Language Learning) and

Iranian EFL Learners' Social Anxiety and Loneliness

realm of language learning. To ensure the ultimate achievement, it is required to research and design the most viable programs and applications.

Determining the role of learners' characteristics and emotional status in the process of language learning via mobile phone will enable the software developers to produce more effective personalized programs. It also can reveal some implications for innovative ways of using new technologies besides offering how to make the most of using them.

The role of learners' social anxiety and loneliness in MALL have received scant attention, and the present study attempts to fill this gap in the literature by investigating any kinds of correlation between these learners' characteristics and vocabulary learning in MALL.

\subsection{Review of the Literature}

Social, cultural, and personal factors on the part of language learners have always been under consideration in the domain of learning a foreign language, and finally resulted in the emergence of interdisciplinary fields, such as psycholinguistics and sociolinguistics. From the first steps of principled approaches to language learning/teaching, psychological and sociological factors were integrated with linguistic features. According to Richards and Rodgers (2001), the works of Piaget and Vygotsky, leading to constructivism by putting responsibility on learners and pioneering other learner-centered approaches and suggesting learning a new language through social interactions, highlighted the importance of learners' social and psychological characteristics throughout the processes of learning a foreign language.

\section{Learning Vocabulary}

A major paradigm shift in teaching English trends occurred in the late 1960s, from the Direct Method and Audiolingualism with more emphasis on grammatical structures to the Communicative Approach which emphasized the importance of teaching vocabulary. It was expected that students learn English through communication activities and express themselves as much as possible in the target language which obviously demanded vast knowledge of vocabulary. Vocabulary was no longer treated as secondary and more attention was paid to the grammar of words, to collocations, and to word frequency.Thus, students were exposed to diverse vocabulary and speaking activities to improve their speaking fluency as well as accuracy (Richards and Rodgers 2001). Nunan (1999) asserted that after the decline of structural linguistics, teaching of vocabulary gained its rightful place within the curriculum as the results of developments in comprehension-based approaches besides computer-based language corpora.

About the importance of vocabulary learning, Elias et al. $(1997,38)$ declared that "Key social and emotional abilities include a broadening vocabulary to label a range of feelings in self and others, an improved understanding of how events relate to one another over time, and a more accurate sense of perspective." The importance of vocabulary acquisition for foreign language learners has been highlighted by many researchers, such as Nation (1994 2005, 2011), Laufer and Nation (1999), Schmitt (2000), Read (2000), Gu (2003), and Tellier (2008). 
In the present study, vocabulary is operationally defined as idioms that are widely used in American English. By idioms, we mean expressions which have a meaning that is not obvious from the individual words (McCarthy and O'Dell 2004). They can take different grammatical functions such as verb, noun, adjective, etc.

\section{Mobile-Assisted Language Learning (MALL) and Vocabulary Learning}

MALL is a subarea of the growing field of mobile learning (ML). Sharples (2006, 2) viewed mobile age as an opportunity "to create extended learning communities, to link people in real and virtual worlds, to provide expertise on demand, and to support a lifetime of learning”. Mobile devices range from laptop computers, tablet PCs, Personal Digital Assistants (PDAs), and smartphones to MP4 players, and the present study focuses specifically on the use of smart phones as an assistant to learning English.

Mosavi Miangah and Nezarat (2012, 310-11) discussed the merits and demerits of using MALL for both learners and professionals. They argued that portability and connectivity are two remarkable properties of mobile phones, which enable learners to study every time and everywhere based on their own choice, to access learning material through wireless network, and to communicate and collaborate with other learners as well as instructors through short message service (SMS) and mobile e-mail. Besides, MALL gives the learners control over learning process according to their own cognitive state. Last but not the least advantage of using mobile phones in the process of language learning is its affordable price in comparison to other mobile technologies such as laptop computers. The constraints of mobile phones for the purpose of language learning are the small screen, tiny keypad, multimedia limitations, expensive access to the Internet, and expensive applications that are compatible to mobile phones. A review of studies related to the usage of mobile technologies in language learning from 2015 to April 2019 (Kacetl and Klímová 2019) maintains the noticeable and positive role of mobile learning and names its benefits as improvement in students' autonomy, confidence, motivation and cognitive capacity.

With the widespread use of smart phones, generally, all kinds of education can take advantage of ML. For instance, distance education has benefited from ML. Kong et al. $(2017,1)$ affirmed that "ML amplifies the flexibility of distance and online learning, reducing the significance of geographic location while increasing that of contextuality," and proceeded that "ML empowers students to participate in social networks, access the Internet, retrieve and work on course materials as part of context-aware ubiquitous learning." In fact, the use of smart phones and social media such as Facebook, YouTube, Instagram, Telegram, and so on is so prevalent among students that encourages educational departments to build curriculum delivery mechanisms on social networks.

One of the most available and inexpensive facilities for providing the learners with learning materials is short message service (SMS) as well as mobile e-mail. Mellow $(2005,471)$ introduced three models for SMS mobile phone use within ML: (1) a "push" system, through which the institution decides on the schedule and amounts of messages and pushes them out to all students containing both learning materials and other useful information such as exam room change, and tutorial cancellation. The institution normally pays the cost of messages; (2) a "pull" system, through which learners themselves request and ask for particular information about the course materials, and they should pay the cost of 
The Relationship between Learning Vocabulary via Mobile (Mobile-Assisted Language Learning) and Iranian EFL Learners' Social Anxiety and Loneliness

messages; (3) an interactive model, through which learners and instructors communicate via SMS. Learners ask their questions and request for more information, and instructors give them proper feedbacks. This model is the most expensive ones since many messages are sent and received by both learners and instructors.

According to Çakir $(2016,172)$, mobile technology has dramatically changed the implementation of some techniques and methods of foreign language teaching, and numerous empirical studies have proved MALL as highly influential on the progress of EFL learners. For instance, the findings of $\mathrm{Li}$ and Cummins (2019); Al-Hamad, Al-Jamal and Bataineh (2019); and Han and Keskin (2016) signified the useful role of MALL in teaching and practicing various aspects of the target language, such as to teach and practice vocabulary, to develop writing proficiency, and to practice listening skill and pronunciation.

It is worth mentioning that nowadays with the ubiquitous use of social media offering inexpensive multidimensional facilities of audio and video materials, many institute and learners prefer to use them for the purpose of language learning, and particularly for learning and practicing English vocabulary. Saran et al. (2008) conducted a study to determine and develop effective instructional materials for mobile phones to improve vocabulary acquisition of EFL learners. The participants were provided with definitions of words, example sentences, related visual representations, and pronunciations through multimedia messages. The researchers reported that "the findings of this study demonstrated that using MMS and SMS in enhancing vocabulary knowledge is very effective" (Saran et al. 2008, 43).

According to Li and Cummins (2020), the usage of text messaging in learning academic vocabulary helps students to learn more target vocabularies. Another recent study performed by Al Saidi and Al Shezawi (2020) insists on the effectiveness of learning vocabulary through a vocabulary game designed for smartphones. These findings are aligned with former studies that maintained the positive impact of learning English vocabulary via smartphones. As an example, Wu (2014) conducted an experimental study among 50 ESL college students; the result showed the outperformance of the students who utilized smartphone in the process of vocabulary learning and emphasized the positive effect of this outstanding technology in vocabulary learning. Some other studies have focused on the impact of social media and especially WhatsApp in vocabulary learning. Bensalem (2018) compared the effectiveness of vocabulary learning in WhatsApp with the traditional methods of vocabulary learning among forty EFL students. The researcher found out the students who were assigned as "Experimental group" to use WhatsApp for vocabulary learning not only demonstrated a very positive perception on the usage of WhatsApp but also significantly outperformed in the vocabulary post-test. Gürlüyer (2019) studied the perception of EFL students of vocabulary learning through WhatsApp and examined the effectiveness of this application in the process of vocabulary learning; the findings indicated significant improvement among WhatsApp users, besides the positive perceptions of using this application.

The positive role of MALL in the process of vocabulary learning has been confirmed by numerous studies, such as Fisher et al. (2009); Al-Shehri (2011); Alemi et al. (2012); Agca and Özdemir 
(2013); Ahmad et al. (2017); Nikoopour and Kazemi (2014); Wu (2014); Lin and Yu (2016); and many

others.

The usage of social media installed on mobile phones for vocabulary learning is the focus of the present study. The popularity of social media among people and specially college students, besides the availability and affordability of mobile phones and the Internet connections, were the main reasons for doing the research in this context.

\section{Social Anxiety}

The U.S. Department of Health \& Human Services (2018), in its website, depicts five major types of anxiety disorders: (1) generalized anxiety disorder, which is characterized by chronic anxiety, exaggerated worry and tension without particular reason; (2) obsessive-compulsive disorder (OCD), which is characterized by recurrent, unwanted thoughts and/or repetitive behaviors; (3) panic disorder, which is characterized by unexpected intense fear accompanied by physical symptoms, such as heart palpitations and shortness of breath; (4) post-traumatic stress disorder (PTSD), which occurs after experiencing a serious physical harm or threat; (5) social phobia (or social anxiety disorder), which is characterized by overwhelming anxiety and excessive self-consciousness in everyday social situations.

In the domain of language learning, experts refer to a different type of anxiety, and call it: language anxiety, classroom anxiety, foreign language anxiety, or language learning anxiety. Richards and Schmidt (2010, 313) defined Language anxiety as:

Subjective feelings of apprehension and fear associated with language learning and use. Foreign language anxiety may be a situation-specific anxiety, similar in that respect to public speaking anxiety. Issues in the study of language anxiety include whether anxiety is a cause or an effect of poor achievement, anxiety under specific instructional conditions, and the relationship of general language anxiety to more specific kinds of anxiety associated with speaking, reading, or examinations.

Krashen's affective filter hypothesis highlighted the learners' attitudes and emotional states as affective variables related to second language acquisition. According to research in the realm of second language acquisition, three kinds of attitudinal or affective variables were identified: motivation, selfconfidence, and anxiety (In Richards and Rodgers 2001, 183).

Zheng $(2008$, 9) counted the benefits of studies about language anxiety as (1) increasing the understanding of teachers from learners' perspective; (2) rendering insights for educators to develop proper interventions to reduce learners' language anxiety; (3) rendering insights for all stakeholders to understand the role of language anxiety in language achievement and learning strategies.

Hashemi $(2011,1811)$ presented the origins of language anxiety as "learners' own sense of "self," their self-related cognitions, language learning difficulties, differences in learners' and target language cultures, differences in social status of the speakers and interlocutors, and from the fear of losing selfidentity". Shabani $(2012$, 2378-82) tried to find the causes of language anxiety among Iranian EFL learners. The results of his study suggested significant correlation between foreign language anxiety and the fear of negative evaluation. He also concluded that "The main sources of language anxiety were fear of failing class, unpreparedness of teachers' questions, fear of forgetting vocabulary and structures". 
The Relationship between Learning Vocabulary via Mobile (Mobile-Assisted Language Learning) and Iranian EFL Learners' Social Anxiety and Loneliness

Jee $(2011,171-172)$ explored the effects of utilizing Web 2.0 technology, with the capability of installation on mobile devices, including: Blogging, Wikis, Facebook, Flickr and Google Maps. The findings demonstrated that using these tools in foreign language instruction would result in: "increased authenticity, reduced anxiety with higher motivation, opportunities for learner-centered instruction, enhanced ownership and personal responsibility, significant flexibility in learning preferences and styles, opportunities for meaningful interaction, combining "flow" with fun, and intertwining multimodal input and output".

Gabarre et al. $(2016,93)$ researched the relationship between anxiety and use of Facebook on mobile phones in the language classroom. The results demonstrated learners' positive attitudes towards the use of Facebook in their language course. Facebook by offering a learning environment shared by friends not only improved learning experiences through promoting motivation and self-confidence, but decreased the levels of anxiety.

Social anxiety, in this study, is regarded as the deterrent feeling among some students that prevents them from participating actively and fruitfully in learning process offered in traditional classroom. Students who suffer from social anxiety cannot benefit from learning in groups, and even if they do, it is more probable that the anxiousness reduces their performance in the classroom.

\section{Loneliness}

As maintained by Perlman and Peplau (1981, 33), loneliness has different forms and categories, including loneliness anxiety, which happens because of unfamiliarity with other people; existential loneliness, which is natural part of every ones' life, for instance, the periods of self-confrontation (Moustakas, 1961); loneliness as a temporary state, which is caused by particular event; loneliness as a chronic trait, which is part of someone's character (TIME website); emotional loneliness, which is the lack of interpersonal friendly relationship; and social loneliness, which is the lack of the sense of belonging to a society and social connectedness (Weiss 1973).

The loneliness that some students feel while studying at schools or institutes in public classrooms is the one which has been the subject of research and debates. Jones and Gerig (1994, in Crozier 1997, 192) have reported the results of their systematic observations of the behavior of some students, identified as "silent," as this: "These students considered themselves shy and lacking in self-confidence and feared being embarrassed in front of others."

Ghaith (2003) explored the relationship between forms of instruction, including the cooperative, individualistic and competitive forms achievement in learning EFL and perceptions of classroom climate, including fairness of grading, class cohesion, alienation from school, and social support. The participants of the study were 135 university students. The findings of the study demonstrated that there was a positive correlation between cooperative learning and the students' perceptions of fairness of grading, class cohesion and social support. It is worth mentioning that class cohesion illustrates the satisfaction of students in terms of group working since it gives them the sense of working with friend, 
and that's the quality that lonely students, who prefer to study alone, lack. The results also indicated that the group with higher cooperation obtained better achievement, which implied that student suffering loneliness got lower achievement in EFL.

Kao (2012, 242-243) examined the relationships between personality traits, loneliness, and achievements of EFL learners. The results suggested inter-impact of the variables, and more specifically the negative correlation between loneliness and EFL achievement. It means that learners with higher level of loneliness obtain poorer achievement in studying EFL. The researcher emphasized the importance of teachers' awareness of learners' differences in term of personality traits and loneliness, and also the impacts that such properties may have on EFL learning.

By loneliness, the researchers make reference to a special feeling among some students that makes them lack the sense of belonging in group learning, which is a common phenomenon in traditional classrooms. Such students always find a way to separate themselves from the group of students, which leads to avoiding active participation in class activities. Generally speaking, they have serious difficulty to harmonize with the flow of public classes.

\section{The Purpose of the Study}

Reviewing the literature of studying vocabulary through MALL and the role of social and emotional characteristics of EFL learners in the processes of language learning reveals that scant heed has been paid to such factors in the domain of MALL; therefore this study attempts to explore the relationship between learning vocabulary via mobile and Iranian EFL learners' social anxiety and loneliness. To this aim, the following research questions were posed:

1- Is there a relationship between learning vocabulary via mobile and Iranian EFL learners' social anxiety?

2- Is there a relationship between learning vocabulary via mobile and Iranian EFL learners' loneliness?

\section{Methodology}

\subsection{Design}

Regarding the main classification of research designs, this research was an applied, quantitative, and confirmatory study through which efforts were made to find the answer of the question: what simple relationships exist between variables? Regarding the sampling paradigm, this study was quasiexperimental since convenience sampling was employed, and the sample has not been randomly selected.

\subsection{Participants}

The participants of this study were thirty-two adult intermediate EFL learners, including 17 females and 15 males, who studied English at the University of Zanjan, Iran. They were recruited through purposeful convenience sampling. However, it is believed that the participants were adequately representative of the target population for two reasons: First, the range of the participants' proficiency level which was intermediate could be regarded as the average level of the target population. Second, the noticeably wide range of total scores in all the three questionnaires and also the vocabulary test could 
The Relationship between Learning Vocabulary via Mobile (Mobile-Assisted Language Learning) and Iranian EFL Learners' Social Anxiety and Loneliness

manifest the heterogeneity of the participants with respect to different social and psychological characteristics. Therefore, it is believed that the sample was representative enough to make cautious generalizations.

Their homogeneity in terms of English knowledge was ensured by Oxford Placement Test. They took part in this test prior to the study; in order to avoid any kind of bias, specially the bias of history which means the familiarity of participants with standard proficiency test, and improving internal validity of the study, it was decided to rely on the previous results (Esmaeili 2018). Furthermore, all of the participants were sophomores studying the same major (English Translation) in the same classroom who had passed the same examinations throughout their studies.

\subsection{Materials}

The materials used in the present study were sixty idioms from the two volumes of the book Basic Idioms in American English (1981), compiled by Hubert H.Setzler, through a mobile program (Telegram) aiming at learning English vocabulary. The rationale behind choosing the source of material was the participants' current study at the time. As previously mentioned, the participants were the members of the university class taking a course on "The Use of English Idioms and Expressions in Translation" The textbook of the course was "English Idioms in Use" by McCarthy and O'Dell (2004). Since the participants were provided with British English idioms at the same time of being the subjects of this study, and in order to avoid any kind of bias, it was decided to utilize American English Idioms suitable for intermediate English learners. The selected idioms are among the most commonly used expressions essential for natural, everyday communication of EFL students. A list containing all the idioms covered in the treatment sessions is provided in Appendix A. In addition to the suitability of idioms in terms of their level of proficiency, their novelty, attractiveness, and applicability in the participants' culture were taken into account. It is worth mentioning that in some cases Longman dictionary was used to provide the participants with more examples.

\subsection{Instruments}

Since the present study sought to find possible correlations between variables in short term, it was decided to use some closed-ended questionnaires which were scientifically accepted and numerously cited in academic articles. The utilized instruments were chosen according to their reported reliability coefficients and validity in scholarly articles. The other advantages of these instruments are being timeefficient and objective as well as being easily interpretable.

\subsubsection{Interaction Anxiousness Scale (IAS) (Leary 1983)}

This scale includes 15 items with a paper-and-pencil format, utilized to assess the participants' level of social anxiety (SA) by describing anxious feelings that mostly happen in face-to-face interaction experiences. Respondents should choose on a 5-point Likert-type scale from 1(Not at all characteristic of me) to 5 (Extremely characteristic of me) to determine the degree to which each item describes him or 
her. The scores of items 3, 6, 10, and 15 need to be reversed before summing up with other scores. The total scores for this scale can range from 15 to 75, and the higher scores present higher levels of SA.

The appropriateness of the questionnaire in the local context was checked earlier in a cross-sectional study by Tavoli et al. (2012). The reliability of the scale was ensured through estimating Test-retest reliability and Cronbach's alpha which were.79 and.90 respectively. Furthermore, a significant correlation between the IAS and a similar measure of the trait (i.e. Brief Fear of Negative Evaluation - BFNE) was found which confirms the validity of the instrument. Hence, this scale has acceptable validity and reliability for use among the Iranian students.

\subsubsection{UCLA Loneliness Scale version 3 (ULS) (Russell 1996)}

This scale is a Likert-type questionnaire in pencil and paper format containing 20 items used to assess the participants' subjective feelings of loneliness. Respondents should rate each item from 1 (Never) to 4 (Often). There are nine negatively worded items $(1,5,6,9,10,15,16,19$, and 20) in the scale, which need to be reversed and then scored. Total scores on this scale vary from 20 to 80 . The higher scores indicate higher degrees of loneliness.

Russell $(1996,20)$ reported the psychometric analyses of this scale as "high reliability in terms of both internal consistency (coefficient $\alpha$ ranging from.89 to.94) and test-retest reliability over a 1-year

period $(r=.73)$. Convergent validity for the scale was indicated by significant correlations with other measures of loneliness."

Vassar and Crosby $(2008,604)$ reviewed 213 studies which utilized UCLA loneliness scale, among them 88 studies computed the psychometric qualities of the scale, 13 of which had utilized UCLA loneliness scale (version 3) and reported the range of the reliability from.86 to.95.

In Iranian context, Bahirayi, Delavar and Ahadi (2006) examined the reliability and validity of the measure among university students. There found to be four emerging factors accounting for $51.2 \%$ of the total variance of the scores. The factors are "feelings of isolation", "having a companion in life", "having something to share with others", and "being sociable". The Cronbach's alpha was reported as.889 which is quite satisfactory, while the convergent validity index was.55 at.001 significance level. On the whole, the results demonstrated that the scale is suitable for use among Iranian university students.

\subsubsection{The Achievement Test (AT)}

A researcher-designed achievement test administered in order to examine the participants' performance on English vocabulary. The test format was chosen as multiple choice questions restricted to 20 items that should be answered in 10 minutes. The scores would range between 0 and 20 . All these choices were made to avoid bringing about threatening, exhausting, or boring experience besides being objective in terms of both devising the items and scoring them. Attempts were made to ensure the validation of the test by: (1) improving the design and appearance of the test, as well as avoiding any kinds of pattern in selection of options and answers; (2) covering the whole content, and avoiding idioms not found in material; (3) choosing multiple-choice form in order to be objective in testing, scoring, and interpreting results; (4) trying to avoid biases which may lead to interference in the purpose of measuring 
The Relationship between Learning Vocabulary via Mobile (Mobile-Assisted Language Learning) and Iranian EFL Learners' Social Anxiety and Loneliness

the participants' idiom knowledge; (5) trying to avoid signaling any kinds of clue for choosing the correct option, for instance based on the grammatical knowledge, or by contrast, any kinds of clue which may distract the examinees' attention from finding the correct answer. Besides, the test was proofread by two professors of English Language Department at the University of Zanjan.

The reliability of the AT was scrutinized by pilot testing. The examinees of the pilot testing were 15 Iranian EFL sophomores at the University of Zanjan who studied English Literature as their major. The Cronbach's alpha coefficient as the indicator of the test reliability offered a satisfactory level of internal reliability $(\alpha=.711, \mathrm{p}<.001)$.

Experts' judgment was sought to estimate the validity of the test. Two professors with related major were asked to judge the validity of the researcher-designed test through answering a questionnaire including four types of test validity (face, content, criterion-related, and construct validity). The questionnaire was a Likert-type scale in which responses vary from1 to 5: 1 (strongly disagree), 2 (disagree), 3 (neither agree nor disagree), 4 (agree), and 5 (strongly agree).

The means of the obtained scores from two raters were 4.00 and 4.25 from 5 , which were above the average and manifested reasonable degree of validity in terms of face, content, criterion-related, and construct validity. In order to measure the inter-rater reliability of the two expert judgments, Cohen's kappa ( $\kappa)$ was run. This measure revealed the significantly acceptable degree of inter-rater agreement between the two raters of the test validity: $\kappa=.636, \mathrm{p}<.05$.

\subsection{Procedure}

As the first step, 32 college students at the University of Zanjan who studied English translation as their major were chosen to be the subjects of the study through convenience sampling. They were regarded as a representative sample of target population of the study, who are Iranian FEL learners, theoretically with the average knowledge of English language that is intermediate learners. Since the sample's members had been the subjects of several studies before then and had taken many standard placement tests, it seemed more appropriate to rely on the result of their previous proficiency test which classified all the members as intermediate EFL learners through Oxford Quick Placement Test reported by Esmaeili (2018).

Searching and gathering information about the most proper instruments and source of materials for treatment were the next steps. After meticulous investigation, two volumes of the book Basic Idioms in American English (1981), compiled by Hubert H.Setzler, were chosen as the source of material, and two questionnaires, namely, Interaction Anxiousness Scale (IAS) (Leary 1983) and UCLA Loneliness Scale version $3(U L S)$ (Russell 1996) were picked as instruments to assess the participants' social anxiety and loneliness respectively. The conformity of these measures to the local context was demonstrated in relevant studies (Bahirayi, Delavar and Ahadi 2006; Tavoli et al. 2012).

At the first session of meeting the participants, they were provided with adequate information about the topic, purpose, implications, benefits, and procedures of the study, and also about the ethical matters, including the confidentiality of their identity and other obtained data from the questionnaires and 
achievement test. Then, they were asked to fill out the questionnaires carefully and completely. Besides, the counterparts of the challenging expressions were introduced in the participants' mother tongue in order to ease and ensure the accuracy of the answers.

After ensuring that all of the participants have easy and unlimited access to the Internet and Telegram software via their mobile phones, the next step was creating a channel in Telegram and registering all of the participants in it, so that they were able to study the materials via their mobile phones every time, everywhere, and as much as they want to.

The six-week period of treatment started the following day. Per week after counseling with the professor of their related course, ten idioms were put in the channel, including their meaning and sufficient examples in the form of sentence. In some cases, if it seemed necessary, more examples were chosen from Longman dictionary and became available in the channel. Six weeks later, the participants were provided with sixty American idioms. The period of treatment lasted to the end of the semester, and the achievement test was taken 10 minutes prior to the participants' final examination of their college course.

In order to investigate the correlation between the learners' performance on the vocabulary test and their social anxiety and loneliness, simple regression was employed. To this aim, the linear association between the variable of learning vocabulary on one hand, and social anxiety and loneliness on the other hand was estimated. All the obtained data were analyzed through precise and meticulous procedures of the latest version of Statistical Package for Social Sciences (SPSS).

\section{Results}

Descriptive and inferential statistics were used to analyze the obtained data from two psychological questionnaires and one researcher-designed achievement test.

\subsection{Descriptive statistics}

The following table demonstrates the descriptive analysis of the participants' answers to Interaction Anxiousness Scale (IAS), UCLA Loneliness Scale version 3 (ULS) and the Vocabulary test

Table 1: Mean and Standard Deviation (SD) of IAS, ULS, and VT scores

\begin{tabular}{lccccccc}
\hline & \multicolumn{4}{c}{ Skewness } & \multicolumn{2}{c}{ Kurtosis } \\
\cline { 2 - 8 } & $\mathbf{N}$ & Mean & Std. Deviation & Statistic & Std. Error & Statistic & Std. Error \\
\hline The scores of IAS & 32 & 2.54 & .70630 & .104 & .414 & -1.325 & .809 \\
The scores of ULS & 32 & 2.834 & .58674 & .015 & .414 & -.861 & .809 \\
The scores of VT & 32 & 16.81 & 2.65716 & -.918 & .414 & -.013 & .809 \\
\hline
\end{tabular}

The mean score of IAS was found 2.54 out of 5 , which was very little above the average. The standard deviation was found.70 denoting rather high diversity among the participants' IAS scores. The amounts of skewness and kurtosis suggest approximately normal distribution, and meet, therefore, the basic assumption of Regression analysis.

As for the descriptive statistics of the participants' answers to UCLA Loneliness Scale version 3, the mean score of ULS was 2.83 out of 4 . The standard deviation was found.58, which is fairly small 
The Relationship between Learning Vocabulary via Mobile (Mobile-Assisted Language Learning) and Iranian EFL Learners' Social Anxiety and Loneliness

suggesting equality of the participants' level of loneliness. The amounts of skewness and kurtosis revealed a very small violation from normal distribution which could be overlooked.

With regard to the participants' scores of the vocabulary test, the mean score of the VT was found 16.81, which was largely above the average and signified the efficacy of the treatment. The standard deviation was found 2.65 suggesting wide range of test scores between 10 and 20. Since the distribution of the scores was negatively skewed, one outlier was detected and removed from the data, which resulted in the approximate normality and decrease of the sample's population to 31 . The omission of the outlier promoted the normality of the data distributions of all other variables, and consequently raised the level of accuracy in calculating correlation coefficients. The normality of the scores' distribution after removing the outlier is shown in the Table 2.

In terms of the normality of the distribution, the results of Kolmogorov-Smirnov and Shapiro-Wilk tests are displayed in the table below.

Table 2: The normality of the distribution of IAS, ULS, and VT scores

\begin{tabular}{lcccccc}
\hline \multirow{2}{*}{ The scores of IAS } & \multicolumn{3}{c}{ Kolmogorov-Smirnov } & \multicolumn{4}{c}{ Shapiro-Wilk } \\
\cline { 2 - 7 } & Statistic & df & Sig. & Statistic & df & Sig. \\
\hline \multirow{3}{*}{ The scores of ULS } & .143 & 32 & .095 & .916 & 32 & .016 \\
The scores of VT & .069 & 32 & $.200^{*}$ & .976 & 32 & .670 \\
\hline
\end{tabular}

*. This is a lower bound of the true significance.

a. Lilliefors Significance Correction

The accuracy of the input data has been examined several times, and in some cases, some participants were asked to fill out the questionnaires again. All the processes of gathering data were carefully supervised and the vitality of gaining accurate information was clarified to all of the participants.

\subsection{Inferential statistics}

In order to examine the relationship between each independent variable, i.e. social anxiety and loneliness, and the dependent variable, which is vocabulary learning, simple regression analysis was applied. To assure the appropriateness of using this scale, the six required assumptions were investigated, including (1) continuousness of data; (2) linear relationship between the two variables; (3) no significant outliers; (4) independence of observations; (5) homoscedasticity; and (6) normal distribution of errors/residuals. Some of the statistical procedures of investigating the assumptions are presented below. In terms of the first assumption, the nature of scores related to each variable, as described in the Instrument section, is continuous. The results of descriptive analyses for three variables of this study, presented in tables above, suggest the normal distribution of data, which meets the sixth assumption. Although the scatter plots of the two sets of variables illustrated in figures 1 and 2, offered no correlation between variables, simple regression scale was employed to analyze the relationships more precisely. 
Mohammadi Masoumi

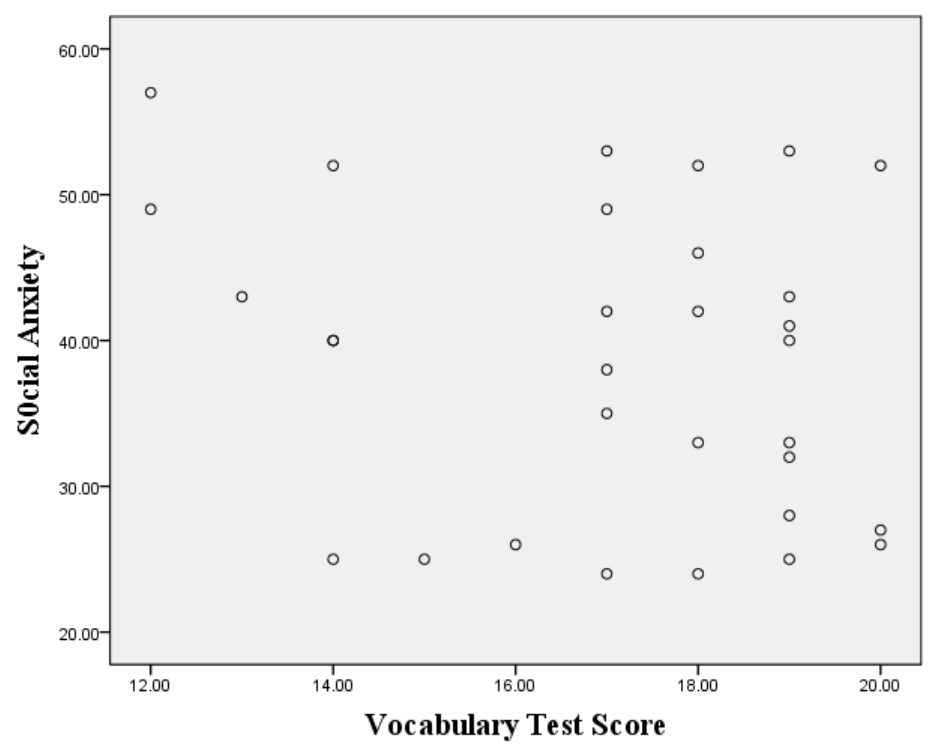

Figure 1: The Scatter plot of Social Anxiety and the Vocabulary Test Score.

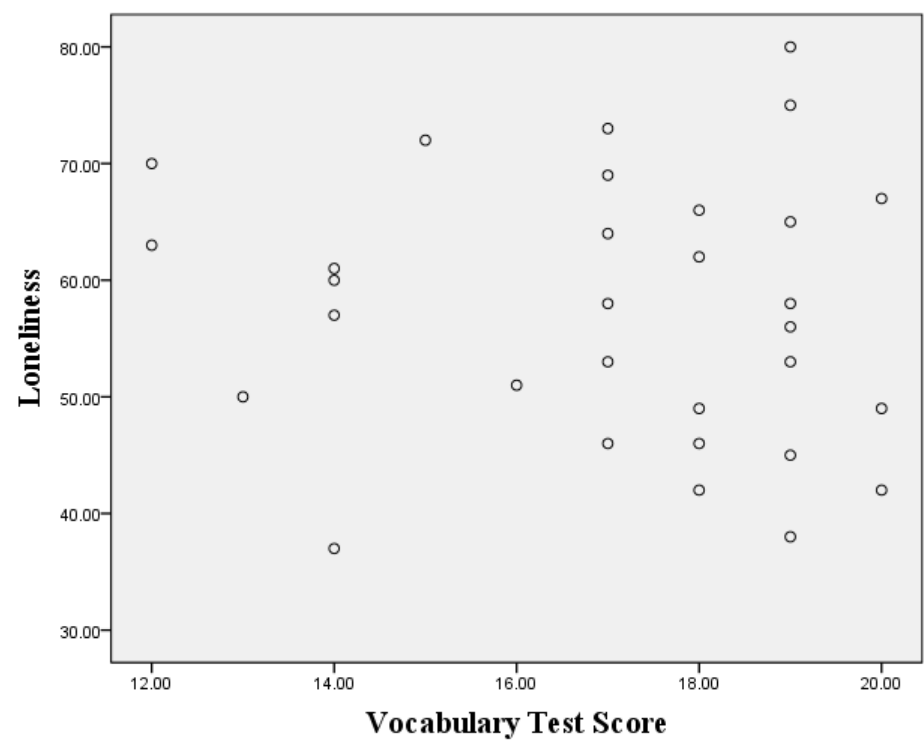

Figure 2: The Scatter plot of Loneliness and the Vocabulary Test Score

The results of simple regression analyses between social anxiety as independent variables and vocabulary learning as a dependent one are presented in Tables 3, 4, and 5.

Table 3: Model Summary ${ }^{\mathrm{b}}$

\begin{tabular}{|c|c|c|c|c|}
\hline Model & $\mathbf{R}$ & R Square & Adjusted R Square & Std. Error of the Estimate \\
\hline 1 & $.247^{\mathrm{a}}$ & .061 & .029 & 2.35284 \\
\hline
\end{tabular}


The Relationship between Learning Vocabulary via Mobile (Mobile-Assisted Language Learning) and Iranian EFL Learners' Social Anxiety and Loneliness

The $\mathrm{R}$ value in Table 3 represents the simple correlation as.247, which indicates a low degree of correlation, and the $\mathrm{R}^{2}$ value indicates that only $6.1 \%$. of the total variation in the dependent variable can be explained by the independent variable i.e. social anxiety. This proportion is too small and suggests no significant correlation between the independent variable and the dependent variable.

Table 4: ANOVA $^{\mathrm{a}}$

\begin{tabular}{llccccc}
\hline & Model & Sum of Squares & Df & Mean Square & F & Sig. \\
\hline & Regression & 128.226 & 1 & 128.226 & 86 & $.001^{\text {b }}$ \\
1 & Residual & 42.742 & 29 & 1.474 & & \\
Total & 170.968 & 30 & & & \\
\hline
\end{tabular}

a. Dependent Variable: Vocabulary Test Score

b. Predictors: (Constant), Social Anxiety

Table 4, ANOVA, shows that this regression model predicts the dependent variable significantly well $(\mathrm{p}>.005)$.

Table 5: Coefficients $^{\mathrm{a}}$

\begin{tabular}{|c|c|c|c|c|c|c|}
\hline & \multirow{2}{*}{ Model } & \multicolumn{2}{|c|}{ Unstandardized Coefficients } & \multirow{2}{*}{$\begin{array}{cc}\begin{array}{c}\text { Standardized } \\
\text { Coefficients }\end{array} \\
\text { r } & \text { Beta }\end{array}$} & \multirow[t]{2}{*}{$\mathbf{T}$} & \multirow{2}{*}{ Sig. } \\
\hline & & B & Std. Error & & & \\
\hline \multirow[t]{2}{*}{1} & Constant & 19.199 & 1.634 & & 11.749 & .000 \\
\hline & Social Anxiety & -.843 & .614 & -.247 & -1.372 & .001 \\
\hline
\end{tabular}

a. Dependent Variable: Vocabulary Test Score

The above table provides this formula for predicting the dependent variable:

Vocabulary Test Score $=19.199-(.843 *$ Social Anxiety $)$

However, this formula only counts for $6.1 \%$ of variation in the dependent variable.

In terms of loneliness, the above procedures led to the results shown in Tables 6,7 , and 8

Table 6: Model Summaryb

\begin{tabular}{ccccc}
\hline Model & R & R Square & $\begin{array}{c}\text { Adjusted } \\
\text { R Square }\end{array}$ & $\begin{array}{c}\text { Std. Error of } \\
\text { the Estimate }\end{array}$ \\
\hline 1 & $.102^{\mathrm{a}}$ & .010 & -.024 & 2.41528 \\
\hline
\end{tabular}

a. Predictors: Loneliness
b. Dependent Variable: Vocabulary Test Score

The $\mathrm{R}$ value in Table 6 represents the simple correlation as.102, which suggests a very low degree of correlation, and the $\mathrm{R}^{2}$ value indicates that only $1 \%$. of the total variation in the dependent variable can be explained by the independent variable i.e. loneliness. In fact, this proportion shows there is no significant correlation between loneliness and vocabulary learning via mobile phone.

Table 7: ANOVA $^{\mathrm{a}}$

\begin{tabular}{llccccc}
\hline Model & $\begin{array}{c}\text { Sum of } \\
\text { Squares }\end{array}$ & Df & $\begin{array}{c}\text { Mean } \\
\text { Square }\end{array}$ & F & Sig. \\
\hline 1 & Regression & 129.883 & 1 & 129.883 & 92 & $.000^{\mathrm{b}}$ \\
& Residual & 41.085 & 29 & 1.416 & & \\
Total & 170.968 & 30 & & & \\
\hline
\end{tabular}

a. Dependent Variable: Vocabulary Test Score

b. Predictors: (Constant), Loneliness 
Table 7, ANOVA, represents that the regression model predict the dependent variable significantly well ( $\mathrm{p}>.005)$, which means this model fits the data.

Table 8: Coefficients ${ }^{\mathrm{a}}$

\begin{tabular}{|c|c|c|c|c|c|}
\hline \multirow[t]{2}{*}{ Model } & \multicolumn{2}{|c|}{$\begin{array}{l}\text { Unstandardized } \\
\text { Coefficients }\end{array}$} & \multirow{2}{*}{$\begin{array}{c}\begin{array}{c}\text { Standardized } \\
\text { Coefficients }\end{array} \\
\text { Beta } \\
\end{array}$} & \multirow[t]{2}{*}{$\mathbf{T}$} & \multirow{2}{*}{ Sig } \\
\hline & B & Std. Error & & & \\
\hline Constant & 18.267 & 2.268 & & 8.055 & .000 \\
\hline Social Anxiety & -.431 & .777 & -.102 & -.555 & .000 \\
\hline
\end{tabular}

a. Dependent Variable: Vocabulary Test Score

Table 8 provides this formula for predicting the dependent variable:

Vocabulary Test Score $=18.267-(.431 *$ Loneliness $)$

However, it only counts for $1 \%$ of variation in the dependent variable.

The results of the regression analysis, represented in the tables above, revealed no relationship between learning vocabulary in MALL and the learners' social anxiety and loneliness as the proportion of prediction was too small, and consequently does not differ from zero. In other words, there is no significant relationship between learning vocabulary in MALL and the learners' social anxiety and loneliness.

\section{Discussion}

The results, reported in the previous section, indicated that no relationship exists between the independent variables under scrutiny (i.e. social anxiety, loneliness) and the dependent variable of learning vocabulary through MALL. This is explicable in light of self-medication hypothesis and selfregulation theory derived from it (Khantzian 1999). In this framework, individuals who are socially anxious benefit from specific services on the Internet to help them cope with their anxiety and associated emotional difficulties. The finding of the present study is also in line with Shepherd and Edelmann (2005), who probed the self-regulation model in relation to social motives for internet use and found that individuals with social anxiety and low ego strength are more likely to use the internet as a medium for self-regulation. Their findings suggested that university students struggling with social anxiety may turn to the internet as a way of regulating, challenging, or escaping their social fears. Likewise, in an earlier research by LaRose et al. (2003) the media was regarded as a channel through which people can consciously relieve their boredom, lessen loneliness, engage in parasocial interaction, or seek validity of social identity. This is also in accordance with the current results that showed MALL successfully minimized the role of loneliness and social anxiety; participants with high levels of social anxiety and loneliness were capable of surpassing these barriers in learning foreign language elements.

The finding is also congruent with Russell and Topham (2012) who examined the impact of social anxiety on student learning. They suggested that the pedagogic intervention for people suffering from social anxiety be provided in a normative framework. Such interventions would benefit not only students with social anxiety but also the wider student population. An example of this intervention in a classroom 
The Relationship between Learning Vocabulary via Mobile (Mobile-Assisted Language Learning) and Iranian EFL Learners' Social Anxiety and Loneliness

is the treatment implemented in this study. They concluded that teachers should follow general pedagogic approaches to reduce potential performance anxiety and embarrassment for all students.

The non-existence of any relation between the learner-related characteristics and leaning vocabulary via mobile is also attributable to the age range of the participants in this study. The learners were either in their late adolescence or early twenties which are characterized by their reluctance to communicate in the real world due to changes of hormone levels in puberty and instead fulfill their social need in the environment of online communication (Esfandiari et al. 2013). The students benefit from the MALL treatment regardless of their score on social anxiety scale that is accountable by their viewing of virtual world as a safe place to get rid of their concerns and fears of real interactions.

The outcome of the current research corroborates the findings of several studies that highlight learners' autonomy in technology-based learning. For instance, Zhou (2016) based on structural equation modeling analysis of his model of second language learning showed that students who experienced social anxiety in language learning felt less autonomous, held weaker orientations of collaborative learning, and were less successful in their English learning. As communication is an integral part of language learning, students who developed a fear of it would find studying in a group more threatening. In response to the high-anxiety context of traditional classrooms, MALL is proposed as a more peaceful and low-anxiety environment (Han and Keskin 2016; Machmud and Abdulah 2017). Kim et al. (2013) found that students who used their own mobile devices expressed positive feelings and had a personalized learning experience out of class time. The positive learner's attitude toward using mobile devices in learning a language gives way to developing learner autonomy (Korlu and Mede 2018). Considering the negative relationship between students' autonomy and their social anxiety (Zhou, 2016), it is implied that the increase in participants' autonomy during MALL is accompanied by lower levels of social anxiety and the students would gain equally from the instruction. This, per se, lends credence to the finding of the present research.

Regarding the lack of relationship between loneliness and learning vocabulary in MALL, the result is consistent with Kao's study (2012). While higher level of loneliness was found to be related to poorer EFL achievement in traditional classroom context, the present study indicates that there is no significant correlation between loneliness and learning vocabulary in MALL, which means that learners with different level of loneliness can benefit all the same from studying EFL in MALL.

With respect to loneliness, Morahan-Martin and Schumacher (2000) utilized the same instrument (UCLA Loneliness Scale) and concluded that higher level of loneliness led people to less social relationships in the real world and more use of the Internet. This, in turn, culminated in the participants' being socially disinhibited online. Accordingly, Internet in general and social media in particular can be justly recognized as a socially liberating environment for learning a foreign language. They are capable of minimizing the possible intervention of some socially and emotionally affective variables, such as social anxiety and loneliness, in language learning. 


\section{Conclusion}

The highlight of the present study was to demonstrate the efficacy of MALL in leaving behind the learners' psychological and social characteristics. The main finding serves as a further proof to the credibility of Krashen's affective filter hypothesis; learners who received instruction in MALL would pass the hindrances caused by their feelings of anxiety and loneliness and make the most of "input" (Richards and Schmidt 2010, 16). The fact that both low-anxiety and high-anxiety learners profit equally from the treatment, underscores the necessity of investing in MALL. Teachers should also acknowledge the potentiality of smart phones (their availability, affordability, and utility) and get familiar with various applications and programs suitable for learning EFL as complementary appliances in traditional context, or even as independent facilities which improve the learners' autonomy. The current study was a step, though small one, towards this direction where we have unraveled the liberating feature of learning EFL through a Telegram channel.

However, this work is not without limitations. The restriction of time, accessibility to resources and number of participants are among the impediments to this research. With respect to the number of participants, it should be noted that since the researchers had limited access to potential learners from the target population, the convenience sampling was employed; this may result in the restriction of generalizability of the findings. Disregarding the gender of the subjects in the process of data analysis is another source of limitation.

Future work could follow a similar path with learners from a different proficiency level. Besides, the nationality and, consequently, the cultural and political environment may play influential roles in learning language skills via mobile devices and lead to different results. Another potential direction for future research would be to include learners' attitude towards MALL and analyze the data in light of such predispositions. Moreover, comparing the effectiveness of different forms of e-learning can open up another venue for further research. According to Hampel (2012), distance learning, for example through MALL, may give learners the sense of loneliness as it lacks interaction with others. At the present study, the relationship between the researcher and subjects was unilateral, without interaction between the participants together or between the researcher and participants. Thus, it would be worthwhile to explore the role of learners' socio-affective characteristics in a virtual context wherein online communication between learners and their instructor(s) is necessary. 
The Relationship between Learning Vocabulary via Mobile (Mobile-Assisted Language Learning) and Iranian EFL Learners' Social Anxiety and Loneliness

$$
\begin{aligned}
& \text { العلاقة بين تعلُم المفردات عن طريق الهاتف المحمول (تعليم اللفة بمساعدة الهاتف المحمول) } \\
& \text { القلق الاجتماعي والشعور بالوحدة عند متعلّمي اللفة الإيرانيين } \\
& \text { إلهام محمدي، عزام معصومي الإنجية }
\end{aligned}
$$

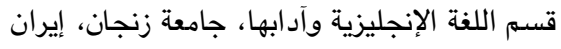

$$
\begin{aligned}
& \text { الملخص }
\end{aligned}
$$

تقوم هذه الدراسة بالبحث في العلاقة بين تعلْم المفردات عن طريق الهاتف المحمول والقلق الاجتماعي والثعور بالوحدة لدى طلاب اللفة الإنجليزيّة بوصفها لفة أجنبية. ولهذا الفرض، تم إعطاء 60 مصطلحاً شائعاً في اللفة الإنجليزية، للمشاركين في هذه الدراسة البالغ عددهم 32 شخصاً من طلاب اللفة الإنجليزيّة بجامعة زنجان وذلك عن طريق قناة في التيليجرام ولمدة 6 أسابيع. وأخيراً تمّ تقييم أداء هؤلاء الطلاب من خلال إجراء اختبار المفردات. ولأجل قياس القلق الاجتماعي والشعور بالوحدة عند الطلاب، تم استخدام استبيان مقياس القلق في التفاعل مع الآخرين (ليري 1983 م) والإصدار الثالث من مقياس الشعور بالوحدة لجامعة كاليفورنيا بـ(لوس أنجلوس) (راسل، 1996). وأظهرت النتائج، عدم وجود علاقة ارتباط بين المتغيرات، وقادت الباحثين إلى استنتاج أن تعلم اللفة بمساعدة الهاتف المحمول، لا يحرّ المتعلمين من قيود الزمان والمكان فحسب، بل يقلل أيضاً من الآثار المحتملة لتدخل بعض المتفيرات الاجتماعية والعاطفية، بما في ذلك القلق الاجتماعي والثعور بالوحدة. الكلمات المفتاحية: تعلم المفردات، تعلم اللفة بمساعدة الهاتف المحمول، القلق الاجتماعيّة، الثعور بالوحدة. 
Mohammadi Masoumi

\section{References}

Agca, Ridvan Kagan and Selçuk Özdemir. 2013. Foreign language vocabulary learning with mobile technologies. Procedia-Social and Behavioral Sciences 83: 781-785. doi: 10.1016/j. sbspro.2013.06.147

Ahmad, Kham Sila, Jocelyn Armarego, and Fay Sudweeks. 2017. The impact of utilising mobile assisted language learning (MALL) on vocabulary acquisition among migrant women English learners. Interdisciplinary Journal of e-Skills and Lifelong Learning, 13: 38-57. Retrieved October 9, 2020, from http://www.ijello.org/Volume13/IJELLv13p037-057Ahmad3410.pdf

Alemi, Minoo, Mohammad Reza Anani Sarab, and Zahra Lari. 2012. Successful learning of academic word list via MALL: Mobile Assisted Language Learning. International Education Studies 5 (6): 99109. doi:10.5539/ies.v5n6p99

Al Saidi, Fatma Abdullah and Ruqaia Abdullah Al Shezawi. 2020. Smartphones fostering English language learners' vocabulary. Paper presented at 20th TESOL Arabia Conference: methods and means in ELT. Retrieved October 20, 2020 from https://www.researchgate.net/publication/ 341043607_Smartphones_Fostering_English_Language_Learners'_vocabulary

Al-Hamad, Raghda F., Dina A.H Al-Jamal, Ruba F. Bataineh. 2019. The effect of MALL instruction on teens' writing performance. Digital Education Review 35: 289-298.

Al-Shehri, Saleh. 2011. Context in our pockets: Mobile phones and social networking as tools of contextualizing language learning. Paper presented at 10th World Conference on Mobile and Contextual Learning, in Beijing, China. Retrieved October 9, 2020 from http://mlearn. bnu.edu.cn/source/ Conference_Procedings.pdf

Bahirayi, Hadi, Ali Delavar, and Hasan Ahadi. 2006. Standardization of UCLA Loneliness Scale (version 3) on students attending universities in Tehran. Journal of Thought and Behavior in Clinical Psychology 1: 1-13.

Bensalem, Elias. 2018. The impact of WhatsApp on EFL students' vocabulary learning. Arab World English Journal, 9 (1): 23- 38. DOI: https://dx.doi.org/10.24093/awej/vol9no1.2

Çakir, Ismail. 2016. "Mobile-Assisted Language Learning (MALL)". In Current trends in ELT, ed. İsmail Yaman, Emrah Ekmekçi, and Müfit Şenel, 170-190. Ankara: NÜANS.

Corder, Stephen Pit. 1973. Introducing Applied Linguistics. Baltimore: Penguin Books.

Crozier, W. Ray. 1997. Individual Learners: Personality Differences in Education. London: Routledge.

Elias, Maurice J., Joseph E. Zins, Roger P. Weissberg, Karin S. Frey, Mark T. Greenberg, Norris M. Haynes, Rachael Kessler, Mary E. Schwab-Stone, and Timothy P. Shriver. 1997. Promoting Social and Emotional Learning: Guidelines for Educators. Alexandria: Association for Supervision and Curriculum Development.

Esfandiari, Narges, Abolghasem Nouri, Mohsen Golparvar, and Mohammad H. Yarmohammadian. 2013. The relationship between social anxiety and online communication among adolescents in the city of Isfahan, Iran. International Journal of Preventive Medicine 4 (4): 390-395. 
The Relationship between Learning Vocabulary via Mobile (Mobile-Assisted Language Learning) and Iranian EFL Learners' Social Anxiety and Loneliness

Esmaeili, Nazanin. "The association between anxiety and perfectionism in writing: Iranian EFL learners' writing performance on IELTS". Unpublished M.A. Thesis, University of Zanjan, 2018.

Fisher, Tony, Richard Pemberton, Mike Sharples, Hiroaki Ogata, Noriko Uosaki, Philip Edmonds, Anthony Hull, and Patrick Tschorn. 2009. Mobile learning of vocabulary from reading novels: A comparison of three modes. Paper presented at 8th World Conference on Mobile and Contextual Learning, October 28-30, in Orlando, Florida.

Gabarre, Serge, Cécile Gabarre, Rosseni Din, Parilah Shah, and Aidah Abdul Karim. 2016. Addressing foreign language learning anxiety with Facebook. Creative Education 7 (1): 93-104. doi: 10.4236/ce.2016.71010

Ghaith, Ghazi. 2003. The relationship between forms of instruction, achievement and perceptions of classroom climate. Educational research, 45 (1): 83-93. doi: 10.1080/0013188032000086145

$\mathrm{Gu}$, Peter Yongqi. 2003. Vocabulary learning in a second language: Person, task, context and strategies. TESL-EJ 7 (2): 1-25. Retrieved October 11, 2020 from https://www.tesl-ej.org/wordpress/ issues/volume7 /ej26/ej26a4

Gürlüyer, Meriç. 2019. Examining students' perceptions and achievements in terms of the utilization of WhatsApp in learning EFL vocabulary. Kafdăg 4 (2): 173-193. doi: 10.24106/kefdergi.4190

Hampel, Regine. 2012. "Multimodel Computer-Mediated Communication and Distance Language Learning". In The encyclopedia of applied linguistics, ed. C. A. Chapelle, 1-5. Blackwell Publishing Ltd. doi: 10.1002/9781405198431.wbeal0811

Han, Turgay and Firat Keskin. 2016. Using a mobile application (WhatsApp) to reduce EFL speaking anxiety. Gist Education and Learning Research Journal 12 (1): 29-50.

Hashemi, Masoud. 2011. Language stress and anxiety among the English language learners. ProcediaSocial and Behavioral Sciences 30: 1811-1816. doi:10.1016/j.sbspro.2011.10.349

Jee, Min Jung. 2011. Web 2.0 technology meets mobile assisted language learning. IALLT Journal of Language Learning Technologies 41 (1): 161-175. Retrieved March 25, 2018, from http://bib. learnit2teach.ca/blog/web-2-0-technology-meets-mobile-assisted-language-learning/

Jones, M. Gail and Thomas M. Gerig. 1994. Silent sixth-grade students: characteristics, achievement, and teacher expectations. The Elementary School Journal 95 (2): 169-182. doi: 10.1086/461797

Kacetl, Jaroslav and Blanka Klímová. 2019. Use of smartphone applications in English language learning: a challenge for foreign language education. Education Science 9 (3): 1-9. DOI: https://doi.org/10.3390/educsci9030179

Kao, Po-Chi. 2012. Exploring personality traits and loneliness in university EFL (English as a foreign language) learners. New Educational Review 30 (4): 236-245.

Khantzian, Edward. 1999. Treating addiction as a human process. London: Jason Aronson Inc.

Kim, Daesang, Daniel Rueckert, Dong-Joong Kim, and Daeryong Seo. 2013. Students' perceptions and experiences of mobile learning. Language Learning \& Technology 17 (3): 52-73. Retrieved from http://ltt.msu.edu/issues/october2013/kimetal.pdf 
Kong, XinLu, Sirirat Kongkasem, Fay Teplitsky, and Benjamin K S Khoo. 2017. Mobilizing learning in higher education: Developments in teaching and learning practice. Paper presented at 2017 Wireless Telecommunications Symposium (WTS), in Chicago, United States. doi: 10.1109/WTS.2017.7943520. https://ieeexplore.ieee.org/document/7943520/authors\#authors

Korlu, Hakan and Enisa Mede. 2018. Autonomy in vocabulary learning of Turkish EFL learners. The Eurocall Review 26 (2): 58-70. Retrieved October 20, 2020 from https://doi.org/10.4995/ eurocall.2018.10425

LaRose, Robert, Carolyn A. Lin, and Matthew S. Eastin. 2003. Unregulated internet usage: Addiction, habit, or deficient self-regulation?. Media Psychology 5 (3): 225-253. doi: 10.1207/S1532785X MEP0503_01

Laufer, Batia and Paul Nation. 1999. A vocabulary-size test of controlled productive ability. Language Testing 16 (1): 33-51. doi: 10.1177/026553229901600103

Leary, Mark R. 1983. Interaction Anxiousness Scale (IAS). Retrieved July 5, 2020, from https://www.ucm.es/data/cont/docs/39-2013-02-21-About\%20the\%20IAS_English.pdf

Lewis, Michael. 1993. The lexical approach. Hove: Language Teaching Publications.

Li, Jia and Jim Cummins. 2019. Effect of using texting on vocabulary instruction for English learners. Language Learning \& Technology 23 (2): 43-64.

Lin, Chih-cheng and Ya-Chuan Yu. 2016. Effects of presentation modes on mobile-assisted vocabulary learning and cognitive load. Interactive Learning Environments 25 (4): 528-542. doi: 10.1080/10494820.2016.1155160

Machmud, Karmila and Ridwan Abdulah. 2017. Using smartphone-integrated model of teaching to overcome students' speaking anxiety in learning English as a foreign language. Journal of Arts \& Humanities 6 (9): 1-11.

McCarthy, Michael and Felicity O'Dell. 2004. English idioms in use. Cambridge: Cambridge University Press.

Mellow, Peter. 2005. The media generation: Maximise learning by getting mobile. Ascilite 1: 469-476. In Ascilite Conference: Balance, Fidelity, Mobility: maintaining the momentum? Retrieved June 30, 2020, from https://ascilite.org/conferences/brisbane05/blogs/proceedings/53_Mellow.pdf

Morahan-Martin, Janet and Peter Schumacher. 2000. Incidence and correlates of pathological Internet use among college students. Computers in Human Behavior 16 (1): 13-29. doi: 10.1016/S07475632(99)00049-7

Mosavi Miangah, Tayebeh and Amin Nezarat. 2012. Mobile-assisted language learning. International Journal of Distributed and Parallel Systems (IJDPS) 3 (1): 309-319. doi: 10.5121/ijdps. 2012.3126

Moustakas, Clark. 1961. Loneliness. Englewood Cliffs, NJ: Prentice-Hall.

Nation, Paul. 1994. New Ways in Teaching Vocabulary. New Ways in TESOL Series: Innovative Classroom Techniques. Alexandria: TESOL.

Nation, Paul. 2005. Teaching vocabulary. Retrieved June 30, 2019, from http://www.asian-efljournal.com/sept_05_pn.pdf 
The Relationship between Learning Vocabulary via Mobile (Mobile-Assisted Language Learning) and Iranian EFL Learners' Social Anxiety and Loneliness

Nation, Paul. 2011. Research into practice: vocabulary. Language Teaching, 44 (4): 529. doi:10.1017/S0261444811000267

Nikoopour, Jahanbakhsh and Azin Kazemi. 2014. Vocabulary learning through digitized \& non-digitized flashcards delivery. Procedia-Social and Behavioral Sciences 98: 1366-1373. doi: 10.1016/j.sbspro.2014.03.554

Nunan, David. 1999. Second language teaching \& learning. Boston: Heinle \& Heinle Publisher.

Perlman, Daniel and Letitia Anne Peplau. 1981. "Toward a social psychology of loneliness". In personal relationships in disorder, ed. Duck, S., and R. Gilmour, 31-56. London: Academic Press.

Read, John. 2000. Assessing vocabulary. Cambridge University Press, Cambridge.

Richards, Jack C. and Theodore S. Rodgers. 2001. Approaches and methods in language teaching. Cambridge: Cambridge University Press.

Richards, Jack C. and Richard W. Schmidt. 2010. Longman dictionary of language teaching and applied linguistics. Great Britain: Pearson Education Limited.

Russell, Daniel Wayne. 1996. UCLA loneliness scale (version 3): Reliability, validity, and factor structure. Journal of Personality Assessment 66 (1): 20-40. doi: 10.1207/s15327752jpa6601_2

Russell, Graham and Phil Topham. 2012. The impact of social anxiety on student learning and well-being in higher education. Journal of Mental Health (Abingdon, England) 21 (4): 375-385. https://doi.org/10.3109/09638237.2012.694505

Saran, Murat, Kursat Cagiltay, and Golge Seferoglu. 2008. Use of mobile phones in language learning: Developing effective instructional materials. Paper presented at Fifth IEEE International Conference on Wireless, Mobile, and Ubiquitous Technology in Education, in Beijing, China. doi: 10.1109/WMUTE.2008.49.

https://ieeexplore.ieee.org/stamp/stamp.jsp?tp=\&arnumber=4489786\&isnumber=4489772

Schmitt, Norbert. 2000. Vocabulary in language teaching. Cambridge: Cambridge University Press.

Setzler, Hubert H. 1981. Basic idioms in American English. Science Research Associates.

Shabani, Mohammad Bagher. 2012. Levels and sources of language anxiety and fear of negative evaluation among Iranian EFL learners. Theory \& Practice in Language Studies 2 (11): 2378-2383. doi:10.4304/tpls.2.11.2378-2383

Shadiev, Rustam, Wu-Yuin Hwang, Yueh-Min Huang, and Tzu-Yu Liu. 2015. The impact of supported and annotated mobile learning on achievement and cognitive load. Journal of Educational Technology \& Society 18 (4): 53-69.

Sharples, Mike. 2006. Big issues in mobile learning. Report of a workshop by Kaleidoscope Network Excellence Mobile Learning Initiative. Retrieved May, 14, 2018 from https://telearn.archivesouvertes.fr/hal-00190254/document

Shepherd, Robin-Marie and Robert J. Edelmann. 2005. Reasons for internet use and social anxiety. Personality and Individual Differences 39 (5): 949-958. https://doi.org/10.1016/ j.paid.2005.04.001 
Tavoli, Azadeh, Abasali Allahyari, Parviz Azadfallah, Ali Fathi Ashtiani, Mahdieh Melyani, and Mahdi Sahragard. 2012. Validity and reliability of the Farsi version of Social Interaction Anxiety Scale (SIAS). Iranian Journal of Psychiatry and Clinical Psychology 18 (3): 227-232.

Tellier, Marion. 2008. The effect of gestures on second language memorization by young children. Gesture, John Benjamins Publishing 8 (2): 219 - 235.

U.S. Department of Health and Human Services. 2018. What are the five major types of anxiety disorders? Retrieved June 14, 2019, from https://www.hhs.gov/answers/mental-health-23+andsubstance-abuse/what-are-the-five-major-types-of-anxiety-disorders/index.html

Vassar, Matt and James W. Crosby. 2008. A reliability generalization study of Coefficient Alpha for the UCLA Loneliness Scale. Journal of Personality Assessment 90 (6): 601-607. doi: 10.1080/002238 90802388624

Weiss, Robert Stuart. 1973. Loneliness: The experience of emotional and social isolation. Cambridge, MA: MIT Press.

Willis, Dave. 1990. The lexical syllabus. London: Collins ELT.

Wu, Qun. 2014. Learning ESL vocabulary with smartphones. Procedia-Social and Behavioral Sciences 143: 302-307.

Zheng, Ying. 2008. Anxiety and second/foreign language learning revisited. Canadian Journal for New Scholars in Education/Revue canadienne des jeunes chercheures et chercheurs en education 1 (1): 1-12. Retrieved June 29, 2018, from https://journalhosting.ucalgary.ca/index.php/cjnse/ article/view/30393

Zhou, Mingming. 2016. The roles of social anxiety, autonomy, and learning orientation in second language learning: A structural equation modeling analysis. System 63: 89-100. http://dx.doi.org/ 10.1016/j.system. 2016.09.001 
The Relationship between Learning Vocabulary via Mobile (Mobile-Assisted Language Learning) and Iranian EFL Learners' Social Anxiety and Loneliness

\section{Appendix A: Materials}

First week:

1- See about (phrasal verb)

2- Watch out (phrasal verb)

3- Have (give) a taste of (phrasal verb)

4- On the nose

5- (right) Under one's nose

6- Come up with (phrasal verb)

7- Figure (somebody/something) out (phrasal verb)

8- Call on/ upon somebody/ something (phrasal verb)

9- Come up to something/somebody (phrasal verb)

10- Meet (someone) halfway (phrasal verb)

\section{Second week:}

11- Get along with (phrasal verb)

12- Fall for somebody/something (phrasal verb)

13- Get over (something)

14- Let somebody/something down (phrasal verb)

15- To one's face (Say something/tell somebody something to their face)

16- Time after time/ time and time again

17- For good

18- Not on your life

19- Make room for someone/ something

20- Keep (on) doing something

\section{Third week:}

21- A man/woman of means

22- Big shot

23- Hard-hearted

24- Hare-brained

25- Level-headed

26- Live wire

27- Narrow-minded

28- Pig-headed

29- Self-made

30- Soft-hearted 


\section{Fourth week:}

31- Stuffed shirt

32- Wet blanket

33- Windbag

34- Be dead set against

35- Be taken in

36- Be well off

37- Get (somebody/ something) wrong

38- Look down on someone

39- On the go

40- Pushover

\section{Fifth week:}

41- Social climber

42- Take (somebody/something) with a grain of salt

43- Be under (one's) thumb

44- Waste (one's) breath

45- Be cut out for something

46- Go whole hog

47- Have a good head on (one's) shoulders

48- Have what it takes

49- Late bloomer

50- On the ball

\section{Sixth week:}

51- Rave about/over something

52- Take something on the chin

53- As good as one's word

54- Eat one's words

55- Get a word in edgeways/edgewise

56- Have a/some/no/little say in something

57- Under one's breath

58- By heart

59- Get mixed up

60- Pop into one's head/mind 